\title{
A ideologia do jeitinho brasileiro
}

\author{
The ideology of brazilian jeitinho
}

\author{
João Wachelke ${ }^{1}$ \\ Alyssa Magalhães Prado
}

\begin{abstract}
RESUMO: O jeitinho é concebido na literatura acadêmica como uma estratégia criativa de resolução de problemas que pode implicar desrespeito a regras e corrupção, ou como um tipo de corrupção calcado em relações interpessoais. Este trabalho apresenta uma revisão crítica de contribuições acadêmicas sobre o jeitinho nas ciências humanas, indicando a diversidade do conceito e pontos de convergência. Em seguida, defende-se a tese de que o jeitinho opera como uma ideologia que promove a deterioração da identidade social brasileira e oculta a capacidade diferencial das classes sociais de extraírem benefícios a partir da prática, concluindo-se que a ideologia do jeitinho estimula comportamentos egoístas e exacerba desigualdades sociais.
\end{abstract}

Palavras-chave: jeitinho; ideologia; corrupção; identidade; comportamento antiético.

\begin{abstract}
Jeitinho is conceived in the academic literature as a creative problem resolution strategy that may imply rule breaking and corruption, or as a kind of corruption based on interpersonal relationships. This work presents a critical review of academic contributions on jeitinho from the human sciences, signaling the diversity of concepts and points of convergence. Then, we support the thesis that jeitinho operates as an ideology that promotes the deterioration of Brazilian social identity and conceals the different capacity of social classes to extract benefits from the practice, concluding that the jeitinho ideology stimulates selfish behavior and exacerbates social inequalities.
\end{abstract}

Keywords: jeitinho; ideology; corruption; identity; unethical behavior.

A ideia do que é ser brasileiro implica uma série de características, práticas e imagens, símbolos de toda ordem associados à cultura nacional. Segundo Barbosa (2005), um dos traços marcantes da identidade nacional é o "jeitinho brasileiro", expressão que mescla o "jeito", que conforme a língua portuguesa, refere-se ao modo de fazer algo, habilidade, aptidão ou disposição; com a forma diminutiva, que para Buarque de Holanda (1995) é uma predileção cultural que confere conotação familiar e afetiva. Ou seja, jeitinho é um modo especial de fazer as coisas que é familiar e caro aos brasileiros, e para o senso comum, não é uma maneira a ser identificada em quaisquer povos.

A experiência cotidiana e algumas pesquisas empíricas (Almeida, 2012, Barbosa, 2005, Pilati, Milfont, Ferreira, Porto, \& Fischer, 2011, Smith et al., 2011, Smith, Huang, Harb, \& Torres, 2012, Torres, Alfinito, Galvão, \& Tse, 2015) atestam que o jeitinho é amplamente conhecido. No entanto, há diversos sentidos para essa prática ou ritual, caracterizando certa ambiguidade na linguagem popular e divergências na literatura da ciência social brasileira, algumas das quais são apresentadas aqui. Como será trabalhado a seguir, o jeitinho pode ser definido como uma prática associada aos brasileiros que implica a utilização de estratégias

\footnotetext{
${ }^{1}$ Doutor em Psicologia Social e da Personalidade pela Università degli studi di Padova (Itália). Professor adjunto do Instituto de Psicologia da Universidade Federal de Uberlândia (UFU). Coordenador do grupo de pesquisa Eclipse - Laboratório de Ideologia e Percepção Social - Uberlândia, MG, Brasil. E-mail: joao.wachelke@ufu.br.

2 Psicóloga formada pela Universidade Federal de Uberlândia (UFU). Mestranda em Psicologia pela Universidade Federal de Uberlândia (UFU). Integrante do grupo de pesquisa Eclipse - Laboratório de Ideologia e Percepção Social.
} 
pautadas em relacionamentos - simpatia, redes de conhecidos... - e criatividade para obter vantagens pessoais. Frequentemente essas vantagens são consideradas indevidas por desrespeitarem normas, regras ou leis igualitárias.

Nossa tese é a de que o jeitinho brasileiro constitui uma ideologia conservadora, isto é, trata-se de prática que estabelece implicitamente uma interpretação do comportamento dos brasileiros que contribui para preservar e exacerbar hierarquias sociais, bem como promover disposições psicológicas e psicossociais. Organizamos esta contribuição em duas seções. Na primeira, apresentamos as contribuições das ciências humanas para definir o jeitinho e avaliar a percepção da população a seu respeito. Na segunda, definimos nossas concepções de trabalho de jeitinho e ideologia e buscamos desenvolver a tese proposta e suas implicações, baseando nossos argumentos em pesquisas empíricas oriundas das ciências humanas.

\section{O jeitinho na Academia}

\section{O jeitinho para as Ciências Sociais}

As análises fundamentais sobre o jeitinho partiram da antropologia culturalista, voltada para o os costumes e instituições do cotidiano dos brasileiros. Barbosa (2005) baseou-se em testemunhos para identificar o surgimento da expressão "jeitinho brasileiro" nos anos 1950 no discurso popular. Nesse período ocorreu a industrialização brasileira dirigida para a substituição de importações e a sociedade brasileira teria iniciado um processo mais amplo de ocidentalização, o que teria acarretado o encontro de uma cultura personalista e hierárquica tradicional brasileira com a marca da cultura ocidental, o individualismo moderno impessoal.

Conforme DaMatta (1997), é desse encontro de modos de vida que se estrutura o jeitinho como ritual de adaptação. De um lado, teríamos culturas tradicionais que enfatizam laços de convivência e a inserção nas comunidades. Não haveria regras para todos, mas uma primazia dos laços interpessoais na determinação dos destinos de cada um; os desfechos sociais seriam diferentes para membros dos diferentes grupos da sociedade. É a sociedade da "pessoa" subordinada à totalidade do coletivo. As sociedades latinas seriam desse tipo. Contrapondo-se a isso, haveria sociedades em que a noção de indivíduo que vigeria. Nessas sociedades, as pertenças grupais desapareceriam, e perante a Lei e os demais, todos teriam os mesmos direitos. Os desfechos sociais seriam vinculados a regras transparentes e públicas. Não importaria mais quem você é ou conhece para ser cidadão. Esse tipo de sociedade seria a dos países do norte do mundo, como França, Inglaterra, Estados Unidos. Seria um modo de organização e funcionamento social superior, estruturado a partir das necessidades do capitalismo, da economia de mercado e da ideologia liberal.

O dilema identificado por DaMatta (1997) constitui-se numa suposta condição sui generis da sociedade brasileira, um "híbrido", fusão imperfeita da sociedade da pessoa com a do indivíduo, a partir da industrialização brasileira e consequente ocidentalização da nação. Então, num nível superficial, o Brasil seria uma sociedade liberal e moderna com regras impessoais, mas o modo de funcionamento tradicional encontraria modos de infiltrarse e distorcer os procedimentos, constituindo a supremacia do pessoal sobre o impessoal. 
DaMatta (1986) define o jeitinho como um modo de navegação social associado a estratégias para se desvencilhar da burocracia pública. Numa situação em que uma pessoa se defronta com algum entrave legal - por exemplo, precisa realizar algum procedimento adicional para emitir um documento - ela contorna a proibição por meio de um atalho de aproximação com seu interlocutor, o agente público. O ritual não estabelece uma hierarquia, mas cria uma exceção de igualdade baseada na simpatia: quem busca o atalho pode pedir atenção especial por passar por fase difícil na vida familiar, que serve como desculpa para não percebido a necessidade de realização do procedimento. Se o agente público consente, baseado em normas culturais de convívio e imaginando passar por situações semelhantes no futuro, a exceção criada anula o procedimento igualitário e beneficia o solicitante, ali inserindo, de outra forma, a hierarquia social, que não se reflete na relação entre os interlocutores, mas na diferenciação entre a pessoa beneficiada pelo jeitinho e as outras pessoas que façam uso do serviço público e enfrentam os requisitos padrão.

Dando sequência a DaMatta, Barbosa (2005) define o jeitinho como "forma 'especial' de se resolver algum problema ou situação difícil ou proibida; ou uma solução criativa para alguma emergência, seja sob a forma de burla a alguma regra ou norma preestabelecida, seja sob a forma de conciliação, esperteza ou habilidade" (Barbosa, 2005, p. 41). Em seguida, acrescenta mais uma característica essencial: o jeitinho precisa se mostrar efetivo a curto prazo. Para a autora, o jeitinho pode envolver uma ação legal ou ilegal; desrespeitar a lei não é característica necessária. É possível perceber que há diferença considerável entre o jeitinho de Barbosa (2005) e o jeitinho de DaMatta (1986); o segundo, o uso de habilidades interpessoais para obter tratamento especial frente à burocracia pública, diz respeito quase que a um caso específico do primeiro, a resolução de problemas e imprevistos de modo criativo e rápido.

Ademais, Barbosa (2005) propõe uma escala que vai de um polo positivo, o favor, até o negativo, a corrupção. $O$ jeitinho teria posição intermediária ambígua. A principal diferença do jeitinho em relação à corrupção seria que esta implicaria vantagem material (por exemplo, roubo de dinheiro público), enquanto que o jeitinho envolveria pouco ou nenhum dinheiro. As diferenças entre favor, jeitinho e corrupção se situariam mais no contexto das situações avaliadas que em definições abstratas, pois há sobreposição significativa.

A pesquisa de Barbosa (2005) Ihe permitiu identificar discursos populares com valências diferentes sobre o jeitinho. O discurso positivo, das pessoas de menor escolaridade, ressalta a simpatia e compreensão presentes em situações concretas, uma solidariedade humana. Em contraste, há alguns tipos de discurso negativo. Um primeiro deles seria típico de setores mais escolarizados. É mais abstrato, reprova a prática e a iguala à corrupção, condenando também o Brasil, um país de segunda classe, e suas instituições. Demanda mudanças macroestruturais dificilmente realizáveis, como ampla transformação da cultura política e legal, e investimento em educação; mudanças no cotidiano são deixadas de lado. Outro discurso negativo, associado com uma posição de "esquerda", conforme a autora, consideraria o jeitinho um conjunto de valores manipulados pelas elites econômicas para ocultar as contradições do Brasil. Um terceiro discurso negativo seria o de camadas populares, descrentes nas instituições nacionais e possibilidades de mudança, como na expressão comum "esse país não tem jeito"; as pessoas entendem que devem praticar o jeitinho porque todos o fazem, e desse modo precisam evitar ficar em desvantagem.

Barbosa (2005) também contribui para o estudo do jeitinho ao enfatizar um forte componente de identidade social no fenômeno: os brasileiros reconhecem e se identificam 
com o jeitinho. Como a autora afirma, ao associar essa prática ao brasileiro, realiza-se uma homogeneização dessa sociedade, contribuindo para o estereótipo de seu povo. Isso acrescentaria aspectos positivos e negativos à identidade nacional. Do lado positivo, estabelecem-se uma suposta igualdade e justiça social ao resolver imbróglios burocráticos não razoáveis, e características como alegria, cordialidade e simpatia do brasileiro. Porém, do lado negativo, há uma imposição de uma grade de leitura estrangeira proveniente de países desenvolvidos que desqualifica a sociedade brasileira, pois esta parece não se adequar ao funcionamento impessoal e individualista das instituições ocidentais: um país "que não é sério", "que não tem jeito", em que leis não funcionam.

Almeida (2012) avaliou as percepções sociais de uma amostra representativa do Brasil a respeito do jeitinho. Os resultados indicam que os brasileiros entendem o jeitinho como um modo simpático de corrupção sem grandes desvios. Diferenciando jeitinho, favor e corrupção, observou que algumas situações que envolvem vantagem financeira ou funcional, como roubar energia elétrica ou receber salário por dois empregos e trabalhar em um só, são claramente percebidas como corrupção. O favor diz respeito a gentilezas que não infringem nenhuma regra ou prejudicam alguém. O jeitinho seria a "pequena corrupção", como desrespeitar sequência de atendimentos num hospital por ter um médico como conhecido, ou oferecer propina para um guarda de trânsito para se livrar de uma multa. A corrupção seria algo acessível às pessoas com poder, como banqueiros e políticos que realizam grandes manobras ilegais; o jeitinho envolveria situações ao alcance da maior parte da população. Percebe-se nova diferença conceitual em relação a DaMatta $(1986,1997)$ e Barbosa (2005): para Almeida (2012) o jeitinho é um tipo específico de corrupção, que se distingue pelo uso de procedimentos simpáticos socialmente e menor porte ou gravidade da prática.

Para Almeida (2012), o jeitinho se explica por meio de supostos patrimonialismo - o uso da máquina pública do Estado para fins privados pela classe política - e familismo prioridade do favorecimento a familiares na sociedade - brasileiros. O aumento da escolarização seria o caminho para erradicar jeitinho e corrupção, já que a aprovação a ambos diminui com o nível superior: apenas um terço dos respondentes com ensino superior aprova o jeitinho, enquanto que para as camadas com menos anos de estudo a aprovação ultrapassa cinquenta por cento. Contudo, sua própria pesquisa indicou que a proporção de respondentes com ensino médio e superior que declarou já ter feito uso do jeitinho foi maior que a de participantes com menos anos de estudo. $O$ autor explica esse resultado, que vai na contramão de suas projeções, supondo que a menor proporção de uso do jeitinho de participantes com menos escolaridade se deva ao maior desconhecimento do significado da expressão jeitinho.

É importante destacar um contraponto ao entendimento antropológico apresentado do jeitinho. Souza (2015) defende que a ciência social moderna por vezes assume a função de uma ideologia, legitimando privilégios por meio da confiança social de que goza. Para o autor, o culturalismo de DaMatta $(1986,1997)$ é conservador e considera que sociedades avançadas de "primeiro mundo" são qualitativamente diferentes das periféricas, do "terceiro mundo". As primeiras são vistas como modelos da eficiência, e as segundas seriam países em que as coisas deram errado, implicando um atraso que deveria ser compensado pela imitação das sociedades centrais. Para Souza, isso seria incorreto: as contradições do capitalismo estariam presentes em todas as sociedades ocidentais, em graus diferentes. 
Souza (2015) argumenta que o dilema brasileiro de DaMatta (1997) contrapõe o Brasil às sociedades "verdadeiramente" liberais com modernização "bem-sucedida". Em consequência, nesses países não haveria jeitinho ou corrupção, o que é questionado por Souza. Além disso, o fator responsável pela desgraça brasileira e latina estaria no Estado, intervencionista e ineficiente. Souza lembra que o mercado e classes empresariais são convenientemente poupados de críticas, ainda que parte considerável dos problemas ligados à corrupção digam respeito à intrusão desses setores na ação do poder público. Souza defende a tese de que a finalidade do discurso originado da perspectiva culturalista é desvalorizar o Brasil e especialmente o Estado brasileiro para, em contraste, promover o capitalismo liberal. $\mathrm{O}$ jeitinho se insere como um componente desse discurso.

Se DaMatta $(1986,1997)$ menciona o jeitinho como estratégia associada à eliminação de obstáculos burocráticos estatais, Souza (2015) aborda o jeitinho de modo mais geral; opõe-se à satanização do Estado, então, faz mais sentido falar em jeitinho e corrupção generalizados, não somente no contexto de repartições públicas - aliás, entendimento próximo do jeitinho como tipo de corrupção de Almeida (2012), mas sem enfocar a forma e peculiaridades com que o jeitinho é efetuado: simpatia, engenhosidade, e assim por diante. No pensamento de Souza (2015), o jeitinho envolve a ativação de relações sociais privilegiadas, isto é, o apelo a contatos sociais poderosos, que permite resolver problemas frequentemente de modo ilegal ou imoral. Considerando capital de maneira ampla como "...tudo que pré-decide o acesso aos bens e recursos escassos que cada um de nós deseja..." (Souza, 2015, p. 85), essa rede de relações é o que Bourdieu (1986) chamou de capital social, possibilidade de valer-se de favores e auxílio de pessoas com boas condições sociais. É um tipo de capital secundário, isto é, deriva das duas principais formas de capital: capital econômico (riquezas materiais) e capital cultural (repertório de conhecimento cultural valorizado). Em última análise, a condição econômica ou cultural é convertida e transformase em possibilidade de capital social; noutras palavras, ter dinheiro ou conhecimento abre as portas para contatos importantes e seus benefícios. Desse modo, segundo Souza (2015), o jeitinho não é uma opção para todos: a mobilização de capital social, de relações próximas privilegiadas para resolver problemas por atalhos, é um recurso muito mais efetivo para as classes privilegiadas. Assim, dilui-se a noção do jeitinho como recurso democrático; embora todos possam utilizar-se dessa estratégia numa ou noutra situação do cotidiano, a obtenção de resultados que impliquem prejuízos importantes à sociedade seria algo mais associado às pessoas que têm à sua disposição redes sociais mais influentes e ramificadas.

\section{Psicologia Social do jeitinho}

Os psicólogos sociais também se debruçaram sobre o estudo do jeitinho. Dois estudos do grupo de pesquisa Conexão Brasil, dedicado à psicologia nativa brasileira, têm destaque. Pilati et al. (2011) definem o jeitinho como uma estratégia de resolução de problemas de influência social que contorna regras, leis e convenções sociais para atingir um objetivo. Os autores concebem o jeitinho como um recurso para flexibilizar normas rígidas que trazem dificuldades à vida. Por outro lado, a quebra de normas é atenuada devido ao uso da simpatia pessoal, buscando evitar conflitos. Trata-se, portanto, de conceito mais alinhado com o proposto por Barbosa (2005), centrado na resolução de problemas. Após realização de entrevistas, os autores buscaram reconstruir a percepção popular sobre o jeitinho, propondo que relações de poder assimétricas estão envolvidas para que uma pessoa evoque o jeitinho para resolver uma situação. Por sua vez, a estratégia propriamente 
dita por quem se utiliza do jeitinho inclui um combinado de a malandragem - esperteza e uso de engano para tirar vantagem de uma situação -, simpatia para aliviar eventuais conflitos ou divergências, inovação, e o desrespeito às regras vigentes. Como resultantes do processo, há a efetivação de algum dano a outras pessoas, devido ao tratamento diferenciado que beneficia o usuário do jeitinho; e algum modo de compensação, de facilitação da vida cotidiana propiciado pelo jeitinho bem-sucedido. Os autores também apontam uma ambivalência a respeito da avaliação jeitinho, visto ora como positivo, ora como negativo - esta, a visão majoritária. Eles avaliam que a norma social ambígua ocorre porque os brasileiros consideram que o uso do jeitinho é generalizado, isto é, a descrição de um pensamento ou comportamento majoritário, uma norma descritiva segundo Cialdini, Kallgren e Reno (1991), o que faz com que seja uma estratégia tolerada. Entretanto, a quebra de regras que lhe é imanente provoca sua reprovação moral; também é uma norma injuntiva porque o jeitinho é percebido como algo errado. Cabe apontar que o discurso negativo popular da pesquisa de Barbosa (2005) também indica a percepção de que o jeitinho é generalizado, e consiste em norma descritiva.

Em pesquisa subsequente da Conexão Brasil (Ferreira et al., 2012), uma amostra de adultos do Rio de Janeiro e Brasília analisou cenários descrevendo situações do cotidiano, declarando se eram típicos ou não do jeitinho. Posteriormente os autores realizaram uma análise estatística de validade do construto psicológico do jeitinho, culminando em três dimensões explicativas das correlações referentes aos cenários, sintetizando aspectos essenciais já especificados no estudo de Pilati et al. (2011): corrupção - por exemplo, cenários em que um homem pede a um taxista que registre num recibo valor acima do devido, para posteriormente solicitar reembolso da companhia para que trabalha-, criatividade - ex.: situação em que uma mulher vende sanduíches para colegas de trabalho para fazer renda adicional -, e desrespeito a normas - ex.: como quando se "fura" uma fila. Posteriormente, num segundo estudo, os autores indicaram evidências de associações estatísticas das dimensões do jeitinho com variáveis sociodemográficas, outros construtos psicossociais e de personalidade. Para nossos propósitos, cabe ressaltar que corrupção e desrespeito a normas apresentaram as correlações mais fortes entre si quando os participantes tiveram que indicar o quanto se identificavam com cada cenário. Houve correlação moderada entre criatividade e desrespeito a regras nessa situação, e associação fraca entre criatividade e corrupção. Quando os participantes avaliaram os cenários como típicos de um brasileiro, corrupção e criatividade tiveram as maiores correlações com desrespeito a normas, e a correlação mais baixa também foi entre corrupção e criatividade. Além disso, os participantes com maior renda tiveram tendência de pequena magnitude a ter índices de desrespeito a normas mais elevados, o que é uma evidência sugestiva da maior proximidade do jeitinho com as pessoas detentoras de mais capital econômico, dando suporte para as ideias de Souza (2015). As três dimensões do jeitinho tiveram tendências diferentes de associação com a orientação para dominação social (SDO), construto psicológico que indica aceitação e promoção das desigualdades sociais. Na versão individual, as correlações mais elevadas envolveram SDO com corrupção e desrespeito a normas, enquanto não houve associação com criatividade, padrão que se manteve na versão cultural. Por fim, os preditores demográficos, de personalidade e psicossociais de cada uma das dimensões do jeitinho são diferentes. Por exemplo, criatividade tem relação somente com escolaridade, enquanto que o desrespeito a normas se relaciona com renda, fatores de personalidade extroversão e socialização, atitudes morais e outros. 
Uma terceira contribuição da psicologia social é a dissertação de Miura (2012), que construiu medidas psicológicas do jeitinho, e avaliou estatisticamente validade e confiabilidade junto a amostras predominantemente femininas e com alta escolaridade. Uma dessas medidas traz avaliações de contextos em que pode ocorrer o jeitinho, e os resultados revelaram duas dimensões explicativas: o jeitinho simpático, aglutinando aspectos ligados à criatividade, busca de relações pessoais positivas e comportamentos de ajuda; e uma dimensão de malandragem, reunindo o entendimento do jeitinho com a pequena corrupção do dia a dia, uma estratégia voltada para o desrespeito a normas e a busca de flexibilidade. Está aí novamente a ambiguidade do jeitinho: ora positivo, ora negativo. Novamente, chamam atenção padrões diferentes de relação das dimensões com outros fenômenos, como a correlação negativa fraca da simpatia com os valores poder e hedonismo, respectivamente, enquanto a malandragem tem correlações positivas com ambos. Um segundo estudo apresenta uma medida independente de contextos, que descreve comportamentos, e apresenta dimensões próximas das identificadas pela Conexão Brasil: simpatia, criatividade, malandragem, dano a outros e desrespeito a normas. Simpatia correlacionou-se positivamente com criatividade, negativamente com dano a outros e desrespeito a normas, e não teve relação com malandragem. Malandragem e dano a outros correlacionaram-se com o valor poder. A tendência a se envolver em comportamentos moralmente questionáveis teve associação negativa com simpatia, positivamente com malandragem, dano a outros e desrespeito a regras.

De modo compatível com sua orientação disciplinar, o foco das pesquisas dos psicólogos sociais da Conexão Brasil foi definir o jeitinho como um construto psicológico avaliado no indivíduo, o que é diferente da avaliação do jeitinho como ritual ou prática cultural. Os estudos realizados propõem propriedades constituintes do jeitinho que contribuem para avançar a discussão sobre o tema, ao identificar facetas do jeitinho como criatividade, desrespeito a regras e corrupção. O teste empírico de questões envolvendo essas dimensões acrescenta maior formalidade e precisão conceitual ao jeitinho, o que é certamente importante. Por outro lado, podemos também levantar a questão: uma situação é jeitinho se contempla apenas uma ou algumas dessas dimensões, e não todas? Imaginemos o caso mencionado de recibos de taxista superfaturados; trata-se de uma situação que, por si só, descreve uma instância de jeitinho? Ou é corrupção pura e simples? E o caso da vendedora de sanduíches para colegas de trabalho, cenário que a princípio não implica desrespeito a normas ou ilegalidade, podemos falar de jeitinho sem essas características?

A resposta dependerá, novamente, da concepção de jeitinho adotada, e o percurso até aqui indica que DaMatta (1984, 1997), Barbosa (2005), Almeida (2012) e Souza (2015) definiram o fenômeno cada um a seu modo. Os psicólogos sociais da Conexão Brasil estão mais próximos dos termos de Barbosa (2005), mas realizam uma descrição dos componentes do jeitinho separadamente, admitindo instâncias de ocorrência do fenômeno em que somente um deles ocorra - os cenários. Mas para os outros cientistas sociais, a prática do jeitinho deve reter simultaneamente algumas dimensões para manter a identidade do fenômeno. Alguns desses aspectos são características necessárias que devem estar presentes em conjunto para que o jeitinho se configure, outras não são essenciais. Em DaMatta (1986), a definição de jeitinho precisa incluir obstáculos do setor público, simpatia interpessoal e quebra de normas institucionais. Para Barbosa (2005), a ilegalidade é frequente, mas não necessária; o cerne do jeitinho estaria nas características necessárias de 
resolução de problemas, agilidade do processo, e criatividade. Já para Almeida (2012), o jeitinho envolve necessariamente simpatia e corrupção menor. Portanto, são todas definições que exigem a presença concomitante de componentes do jeitinho para caracterizar o fenômeno. Para que a abordagem psicométrica dos estudos psicossociais dos componentes do jeitinho seja compatível com os conceitos sobre a prática social jeitinho vindas das ciências sociais, os componentes devem ser sempre avaliados conjuntamente com outros para caracterizar o jeitinho; isso poderia ocorrer com a construção de cenários mais complexos, incluindo situações com combinações das dimensões identificadas. Mesmo com todas as divergências conceituais, suponhamos que o jeitinho seja definido com características essenciais como criatividade juntamente com pelo menos uma das outras dimensões, desrespeito a normas ou corrupção. Nessa condição, criatividade, por si só, não caracterizaria o jeitinho; mas criatividade que implica o desrespeito a normas ou corrupção, sim. Desse modo, interpretamos que vender sanduíches para colegas de trabalho é algo engenhoso, mas tão somente exemplo de criatividade. Essa prática caracterizará jeitinho somente se, como ilustração, for algo realizado em expediente de trabalho que não poderia ser destinado para outro fim - caso de desrespeito a normas -, ou talvez se o dinheiro para fazer os sanduíches seja desviado de verba para manutenção de escritório - caso de corrupção. Não é nossa intenção indicar algum conceito ou operacionalização do jeitinho como mais ou menos apropriado, mas evidenciar que a literatura em ciências humanas apresenta definições e maneiras de entender o fenômeno consideravelmente diferentes, e propor alguma via de compatibilização dessas diferenças; tomamos o exemplo da operacionalização da Conexão Brasil porque é uma via mais concreta para estudos empíricos.

Com isso, concluímos nossa breve revisão sobre aquelas que julgamos serem as contribuições mais significativas das ciências sociais em geral e da psicologia social. Agora podemos passar ao desenvolvimento da tese do jeitinho como ideologia.

\section{A natureza ideológica do jeitinho}

\section{O essencial do jeitinho}

Mesmo com todas as diferenças conceituais, das análises acadêmicas do jeitinho, há um núcleo comum: o jeitinho envolve quebra de regras ou leis por meio de relações pessoais e frequentemente - embora não necessariamente, para Barbosa - implica a realização de atos ilegais ou imorais com efeitos de pequeno a médio porte, em contraste com a corrupção ou grandes práticas criminais. Considerando esses aspectos comuns, adotamos a seguinte definição essencial do jeitinho: prática de atos ilegais ou imorais de pequeno a médio porte a partir de habilidades e redes de contato interpessoais. Ela contempla boa parte das contribuições da literatura, mesmo sem abarcar toda a diversidade do conceito.

Cabe esclarecer, entretanto, que tratamos apenas do jeitinho "negativo", que implica desrespeito a regras ou desvio; o lado inovador e simpático do jeitinho, a consideração isolada da dimensão de criatividade de Pilati et al. (2011) e Ferreira et al. (2012), o "jeitinho simpático" de Miura (2012), e o "jeitinho positivo" de Barbosa (2005) não estão incluídos na nossa análise. Justificamos isso por duas vias. A primeira diz respeito à possibilidade de que, no conceito do jeitinho, estejam incluídos, de fato, dois jeitinhos. Há evidências empíricas: os 
discursos distintos e autossuficientes sobre os tipos de jeitinho do estudo de Barbosa (2005), e a existência de padrões de correlações diferentes encontrados por Ferreira et al. (2012) e Miura (2012) a respeito das medidas do jeitinho empregadas em suas pesquisas, detalhados anteriormente. Os aspectos considerados positivos do jeitinho (como criatividade, ou simpatia) tendem a covariar e ter relações mais fracas com dimensões como corrupção e desrespeito a regras, que por sua vez têm associações geralmente mais fortes entre si. Além disso, os fatores psicológicos e sociais que predizem os escores nas dimensões do jeitinho são distintos, o que sugere a possibilidade de que se esteja tratando de mais de um fenômeno. Há evidências nessa direção também da pesquisa de Resende (2015), que avaliou relações entre as três dimensões do jeitinho brasileiro e a identidade moral, parte do autoconceito voltada para características morais das pessoas. A dimensão corrupção teve correlações negativas com a internalização da identidade moral, enquanto a criatividade teve relação positiva com a simbolização, a expressão externa dessas características.

A segunda justificativa para lidar apenas com o jeitinho negativo é que o jeitinho positivo não representa problema social: é aceito sem controvérsias. É o jeitinho associado à desonestidade e esperteza que pode desempenhar funções de ideologia e que, portanto, tem nosso interesse aqui. Ademais, esse jeitinho problemático socialmente tampouco exclui procedimentos simpáticos ou inovadores para chegar a seus objetivos; antes, é a existência desses expedientes, assim como o eventual alcance ou porte do ato realizado - mesmo que esta seja uma avaliação subjetiva - que diferenciariam o jeitinho da corrupção, ou pelo menos especificam o jeitinho como um tipo de corrupção. Porém, essas características não são suficientes para defini-lo; é necessária, por esse entendimento, a realização de ato ilegal ou imoral. O jeitinho, neste trabalho, é mais compatível com as concepções de Almeida (2012) e Souza (2015), e é nesse contexto semântico que deve ser entendido. Isso não impede que boa parte de nossa argumentação seja válida para, por exemplo, o jeitinho como resolução criativa de problemas, mas este é mais abrangente e geral e, portanto, qualquer transposição conceitual demanda cautela para situar as implicações discutidas aqui junto às particularidades de cada conceito. Depois de limitar o alcance do jeitinho a que nos referimos, é preciso agora estabelecer o que queremos dizer com ideologia neste trabalho.

\section{Um conceito de ideologia}

Se queremos defender a tese de que o jeitinho atua como uma ideologia, primeiro devemos esclarecer o que entendemos por ideologia. É um conceito entendido de múltiplas formas nas ciências humanas, e, portanto, a adoção clara de uma definição em particular é necessária. Partimos da concepção de Thompson (2011), pensada para o contexto da análise ideológica relacionada ao desenvolvimento dos meios de comunicação de massa. Para Thompson (2011, p. 76), a ideologia refere-se às "...maneiras como o sentido serve para estabelecer e sustentar relações de dominação". Quanto à noção de sentido, Thompson esclarece que trabalha com as interpretações de significados culturais para as pessoas, e enfatiza e sua circulação por meio de formas simbólicas, isto é, ações, gestos, manifestações verbais e pictóricas, enfim, formas variadas de expressão que veiculam conteúdos culturais. A proposta é uma concepção crítica, que para o autor quer dizer que a ideologia é considerada um fenômeno parcial, ilusório ou enganador. Thompson define a ideologia como promotora e mantenedora da assimetria de poder entre divisões sociais, aí incluindo classe, etnias, estados-nação, grupos raciais, gênero ou quaisquer segmentações sociais politicamente pertinentes; o caráter crítico está na contestação dessas relações de 
subjugação de grupos e pessoas por outros, avaliadas como reprováveis, devendo ser identificadas e combatidas. O próprio autor esclarece que a ideologia, em sua definição, é hegemônica, sendo considerada ideologia somente se cumpre a função de preservar o poder de grupos dominantes. Assim, outros significados associados a outros setores da sociedade e que desafiem os sentidos de sustentação da dominação não seriam considerados ideologia, mas formas simbólicas contestatórias, ou uma forma inicial da crítica da ideologia.

Para nossos fins, uma ideologia será definida como uma interpretação a respeito da vida social, com caráter descritivo ou prescritivo, que exerce efeitos políticos. Quando dizemos que uma ideologia é uma interpretação a respeito da vida social, adotamos o significado de interpretação como explicação ou entendimento de algo. A interpretação é sempre uma construção simbólica que se coloca no lugar da realidade, tomando seu lugar; em alguns casos, há interpretações que se sabe serem uma versão dentre várias, em disputa para que sejam reconhecidas como válidas ou mais desejáveis; noutras ocasiões, sua natureza de construção simbólica é opaca, e elas são consideradas pelas pessoas e grupos que as têm como a própria realidade, ou seja, impõem-se como percepções.

As ideologias, enquanto construções simbólicas, têm conteúdos descritivos e prescritivos, isto é, são interpretações de como a vida social é, ou como deveria ser idealmente. Wilson (1992, p. 19) foi feliz ao definir uma ideologia como "...um conjunto de ideias com conotações afetivas que descreve tanto o mundo que é e o mundo que deveria ser". Portanto, nem todas as ideologias são consideradas pelas pessoas que as endossam como retratos fieis e unívocos da realidade. Frequentemente, as pessoas endossam ideologias que guiam suas lutas para definir os rumos que as coisas devem tomar para chegar a uma realidade ideal, seja pela sua transformação ou conservação.

Por fim, quando estabelecemos que as ideologias exercem efeitos políticos, condicionamos sua existência à atuação nas forças de poder da sociedade. Essa atuação pode ocorrer seja na conservação de relações de poder assimétrico em que algum grupo controla os demais - caso em que estamos próximos da sustentação das relações de dominação de Thompson -, seja na transformação dessas relações de poder, quando há ideologias de minorias que tentam confrontar o poder dominante e reduzir sua desvantagem. Então, temos ideologias de manutenção do status quo e de luta por sua mudança. Diferentemente de Thompson, que restringe as ideologias ao caso da dominação, consideramos toda construção simbólica que tem importância em termos de relações de poder como uma ideologia; concebemos o mundo social como uma arena de conflitos por poder, em que as ideias são as armas pela interpretação da realidade e orientação de práticas sociais. Ademais, de modo consciente ou não, práticas compatíveis com as ideologias constituem efeitos políticos relevantes para nós quando contribuem para gerar disposições pessoais e compartilhadas que promovam as relações de poder implicadas por essas ideologias. Assim, não só as interpretações podem ter caráter ideológico, mas também as ações, rituais, hábitos e suas formas institucionais, na medida em que efetivam os objetivos visados numa ideologia. Tendo esboçado as características essenciais de nossa concepção, podemos prosseguir explicando por que o jeitinho funciona como ideologia e descrevendo seus efeitos sociais. 


\section{A ideologia do jeitinho}

É necessário demonstrar que o jeitinho é uma ideologia, isto é, que é compatível com a definição de ideologia que apresentamos. Em primeiro lugar, não é algo difícil de constatar que o jeitinho é uma construção simbólica. A noção de jeitinho sintetiza numa classe de rituais e práticas de ampla diversidade de ocorrências do cotidiano, unificando-as numa abstração explicativa, tanto no senso comum, de modo mais vago, quanto nas ciências sociais, com rigor conceitual, ainda que com amplas divergências, como a revisão realizada aqui indicou. $O$ jeitinho brasileiro é uma interpretação do brasileiro, que supostamente teria dificuldades em lidar com regras impessoais e, fazendo uso de habilidades interpessoais e contatos, buscaria burlá-las. É uma noção construída que, seja verdadeira ou não, toma o lugar da realidade para aqueles que buscam entender a sociedade brasileira a partir dela.

$\mathrm{O}$ aspecto mais importante envolve os efeitos políticos que o jeitinho exerce. Mas que tipo de efeito político pode ser exercido? Identificamos duas consequências psicossociais do jeitinho que contribuem para manter ou acentuar hierarquias de poder no Brasil, isto é, que agem como forças conservadoras: a deterioração da identidade social brasileira e a capacidade diferencial das classes sociais de extrair vantagens a partir do jeitinho.

Passemos então ao impacto presumido do jeitinho na identidade social brasileira. Como tratado na revisão acima, Souza (2015) argumenta que a corrupção, que para ele é outra maneira de se falar do jeitinho, não é algo específico do Brasil, o que seria comprovado pela grande diversidade de escândalos que volta e meia vem à tona nos mais variados países. Porém, para ele, a tese do jeitinho como particularidade brasileira tem sua origem na ciência social brasileira e teve ampla disseminação junto à população a partir das universidades e da mídia, estruturando o imaginário popular de modo a culpar o Estado pelas mazelas nacionais, apresentando o mercado e capitalismo livre como soluções, a despeito de suas contradições. Não retornaremos a essa análise, mas a tomaremos como ponto de partida para desenvolver as consequências psicossociais do entendimento dos brasileiros como um povo corrompido, que é efetivamente sugerido ao tratar o jeitinho como algo específico do Brasil.

Barbosa (2005) ressalta uma diferença importante do jeitinho e de outros rituais e práticas marcadas por criatividade, engano e ilegalidade em outros países: ele possui forte caráter identitário, é parte importante da identidade do brasileiro. Isso quer dizer que o jeitinho e o modo como é avaliado são transpostos para os sentimentos de orgulho ou vergonha, de desesperança ou otimismo, em que cada brasileiro pode se reconhecer. Em favor de Souza (2013), podemos citar uma pesquisa realizada em 2012 e 2013 a partir de percepções de 114 mil habitantes de 107 países sobre percepções de corrupção que indicou que os participantes de 83 países, $77,5 \%$ do total, pensavam que a corrupção havia aumentado nos anos anteriores (Transparency International, 2013). Por sua vez, uma pesquisa de percepções de corrupção realizada em 2015, baseada em opiniões de especialistas de 168 países, destacou que não há país livre de corrupção: mesmo os países escandinavos, que tiveram resultados extremamente positivos, passaram por grandes escândalos de corrupção em 2015 (Transparency International, 2015). Ou seja, há países em que a corrupção é um problema mais grave que em outros, mas é um fenômeno presente em todo o mundo. Ao associar o jeitinho à realidade brasileira como algo exclusivo, há uma nacionalização da pequena corrupção, uma associação forte dessa prática com a população 
nacional, com consequências negativas para a percepção dos brasileiros de si mesmos ou de seus conterrâneos.

Se a corrupção não é exclusividade de alguns países, tampouco é o jeitinho exclusivo do Brasil. Há pesquisas da psicologia social em que práticas consideradas específicas de certos países foram avaliadas quanto à sua tipicidade por nativos, com a finalidade de verificar se eram de fato restritas a certas culturas, ou se estavam presentes em outros contextos. Torres, et al. (2015) observaram que estudantes e gerentes brasileiros consideraram cenários de guanxi, uma prática chinesa baseada em trocas de favores a partir de conexões sociais, mais típicos do Brasil que estudantes e gerentes chineses. Esses participantes também consideraram o jeitinho mais típico do Brasil, mas os chineses avaliaram o jeitinho com escores intermediários, indicando que ele pode ser reconhecido também nessa sociedade. Em pesquisa realizada com estudantes brasileiros, chineses, libaneses e britânicos, Smith et al. (2012), os libaneses consideraram o jeitinho mais típico de sua realidade que os brasileiros. Por sua vez, os brasileiros avaliaram o "pulling strings", obtenção de favores concedidos por pessoas influentes característica do Reino Unido, e o guanxi mais típicos do Brasil que o jeitinho, que teve avaliação também negativa. Em contraste, em estudo de Smith et al. (2011) gerentes brasileiros avaliaram o jeitinho como mais representativo e típico em seu país que as avaliações de gerentes de outros quatro países. Portanto, elementos da prática do jeitinho, avaliada nessas três pesquisas a partir de cenários construídos junto às populações estudadas, também são reconhecidos de modo significativo em outras culturas. Associar o jeitinho somente ao brasileiro não é justificado, e tem consequências psicossociais.

O reconhecimento do jeitinho como prática social por parte da população implica o reconhecimento de que no Brasil o desrespeito a regras e leis é algo recorrente e generalizado, o que é atestado pelos resultados de pesquisa de Barbosa (2005), Almeida (2012) e Pilati et al. (2011): há uma norma descritiva percebida de que o jeitinho é praticado por muitos. Se o protótipo do brasileiro é considerado dessa maneira, a avaliação que dele se faz não é animadora. Na melhor das hipóteses, o brasileiro seria alguém que tenta sobreviver a leis ilógicas que criariam empecilhos não razoáveis, forçando-o a procedimentos ilegais ou paralegais para viabilizar seu cotidiano. Na pior delas, seria um egoísta que busca levar vantagem sobre os demais deliberadamente, ignorando regulamentos e normas supostamente necessários socialmente e igualitários. Em ambos os casos, ocorre o favorecimento de quem se utiliza do jeitinho e prejuízo dos demais.

Um cidadão brasileiro qualquer deveria escolher, portanto, entre ignorar o atalho do jeitinho e suas vantagens, correndo o risco de adotar uma postura vista como ingênua, já que todos empregariam a prática, ou incorrer no jeitinho, seja com algum peso na consciência por saber se tratar de algo repreensível, seja minimizando com a justificativa de seu uso generalizado ou pela ineficácia, inadequação ou ilegitimidade atribuídas às leis. E há evidências que apontam para uma tendência maior a cometer atos reprováveis nesses casos: conforme pesquisa experimental de Köbis, van Prooijen, Righetti e Van Lange (2015), pessoas que percebem um ato corrupto como majoritário ou são informados disso tenderam a cometer mais atos corruptos que os demais.

Uma derivação desse retrato negativo do brasileiro prototípico é também a percepção que o brasileiro passa a fazer de seu país: uma nação caótica, de segunda categoria, em que as regras impõem problemas à população mas ao mesmo tempo não tem validade real, desrespeitadas por todos aqueles que estão em condições de fazê-lo. É o que já foi 
argumentado por Souza (2015), para quem as teorias da modernização, que incluem estudos sobre o jeitinho e o patrimonialismo, disseminam e perpetuam preconceitos nacionais, contribuindo para a percepção dos habitantes das sociedades periféricas, isto é, subdesenvolvidas, como corruptos e inconfiáveis, inferiores aos residentes de países centrais ou desenvolvidos. Isso propicia uma idealização das sociedades ditas avançadas e produz efeitos positivos no imaginário dessas sociedades, suprimindo suas contradições e exaltando qualidades. Em contrapartida, nas sociedades periféricas temos como autopercepção, por exemplo, o brasileiro "complexo de vira-latas", expressão de Rodrigues (1993) empregada numa crônica jornalística para nomear a descrença do brasileiro com a seleção nacional de futebol nos anos anteriores às vitórias nas copas do mundo, posteriormente generalizada para traduzir o sentimento de inferioridade da população comparativamente aos países ditos desenvolvidos. Fischer, Ferreira, Milfont e Pilati (2014) observaram que pessoas menos identificadas com o Brasil - o que imaginamos ser uma consequência provável desse desencanto com o país -, quando se deparam com símbolos ligados à corrupção, apoiam mais as práticas corruptas que aquelas com níveis maiores de identificação. Não é difícil imaginar uma retroalimentação sugerida por esses resultados: diante da concepção de um Brasil desprezível moralmente, as pessoas identificam-se menos com o país e tendem a praticar ilegalidades ou atos reprováveis, já que todos (supostamente) o fazem; então, passa-se a ter uma justificativa real para a avaliação negativa inicial.

É evidente que os problemas de corrupção ou do jeitinho ligados ao Brasil se explicam pela cultura nacional e comportamento dos brasileiros, pois sem práticas corruptas não há corrupção. A questão é que o jeitinho e os discursos ideológicos a ele associados naturalizam e, assim, imobilizam o problema. A narrativa apresentada por essa ideologia é histórica somente no sentido de justificar o estado atual e supostamente irremediável da degradação moral da população e do absurdo das leis vigentes a partir de uma herança maldita portuguesa em termos das instituições nacionais e do roubo de riquezas da colônia, e da posterior constituição de uma classe política que agiria somente em proveito próprio. Essas forças teriam resultado na sociedade e da população brasileira atuais, entendidas como irrecuperáveis, ou quando muito exigindo esforço hercúleo de conscientização e articulação do povo e das instituições para efetivar uma mudança quase impossível. É o cenário formado a partir de uma interpretação histórica discutível do passado e sem expectativa de alteração: um país com passado nefasto e sem futuro. Com isso, a ideologia retira possibilidades de intervenção para combater o jeitinho da esfera do possível concreto. É o "país que não tem jeito", sem solução, ilustrado no discurso de alguns participantes de Barbosa (2005): se tudo é problema, efetivamente não há como resolver problema algum.

Como avalia Souza (2015), o jeitinho funciona como ideologia para construir a imagem do senso comum do brasileiro médio sobre si próprio. E acrescentamos a isso que essa imagem gera uma identidade social negativa, uma autodesvalorização acompanhada por pessimismo, pela desvinculação com o coletivo que apenas contribui para a escolha pelas "soluções" individuais apontadas que nada contribuem para modificar a situação.

Finalmente, podemos abordar a segunda consequência política psicossocial do jeitinho sugerida por nós, as diferenças de capacidade das classes sociais na extração de vantagens a partir do jeitinho. Cabe apontar que, seja na academia seja no discurso popular, o jeitinho é tratado de modo uniformizador e homogeneizante: ao se falar do jeitinho, fala-se de uma característica do brasileiro, deixando de lado suas diferenças em termos de posições sociais. 
Como discutido anteriormente, Souza (2015) apresenta um contraponto ao entendimento de Barbosa (2005) de que o jeitinho seria democrático e acessível a todos. 0 capital social, recurso a relações sociais importantes, reflete a discrepância de recursos disponíveis para ricos e pobres empenharem na prática do jeitinho. Se é verdade que todos podem desrespeitar regras e realizar atos ilegais ou imorais a partir de redes de contato, cabe ponderar que as possibilidades de se beneficiar desses atos são maiores para quem dispõe de melhores condições econômicas. Pensemos nos extremos do espectro social. 0 que um baixo funcionário com atividade de rotina pode fazer que envolva jeitinho? Enganar o supervisor? Sair do trabalho mais cedo? Qual a probabilidade de sua rede de conhecidos ser formada por pessoas influentes e que possam the abrir os caminhos, dando-lhe vantagens indevidas?

As respostas possíveis a essas perguntas, quaisquer que sejam, necessariamente indicam mais limitações que ao pensar nas possibilidades que se apresentam para profissionais liberais com alta escolaridade ou altos funcionários em situações semelhantes, que frequentam círculos sociais que detêm de fato controle sobre instituições ou podem mobilizar recursos econômicos ou culturais em seu proveito. Podemos pensar em exemplos, como planejar o pagamento de impostos para minimizá-los - realizando contabilidade "criativa" ou mesmo sonegando deliberadamente -, contratar advogados para lidar com processos na justiça se necessário, valer-se de amizades e contatos familiares para conseguir uma aprovação facilitada em alguma seleção profissional. As possibilidades de sucesso e o nível de benefícios acessíveis às pessoas com posição social favorável são bem maiores que a realidade dos ocupantes de posições sociais de desvantagem.

Cabe considerar, também, que há estudos internacionais que obtiveram resultados consistentes de que pessoas em posições sociais privilegiadas, isto é, com status socioeconômico ou renda maiores, tendem a se comportar de modo antiético mais frequentemente que pessoas de classes desfavorecidas. Piff, Stancato, Côté, MendozaDenton e Kelther (2012) observaram essa tendência em comportamentos como desrespeitar regras do trânsito, mentir para conseguir vantagens pecuniárias, apanhar doces destinados a crianças e relatar tendências antiéticas no trabalho. Os autores explicaram esse comportamento das pessoas com mais posses por meio de atitudes favoráveis à ganância, que os levariam a valorizar mais o próprio bem-estar e agir de forma independente dos demais. Dubois, Rucker e Galinsky (2015) também conduziram experimentos que lhes permitiram explicar essa associação entre posição social e comportamentos antiéticos pelo aumento da sensação de poder propiciada pela maior renda, que permitiria às pessoas mais ricas buscar suas metas pessoais com menos restrições, o que se associa a mais comportamentos egoístas. Como o jeitinho também envolve o benefício individual em detrimento das regras sociais, é plausível conceber essa associação entre o uso da prática e posições sociais mais favoráveis. É pertinente lembrar que nos resultados de pesquisa de Almeida (2012) referente a uma amostra representativa brasileira, as pessoas com mais escolaridade relataram fazer mais uso do jeitinho que pessoas com baixa instrução, o que é compatível com os resultados de Piff et al. (2012) e Dubois et al. (2015), haja vista que a escolaridade é indicador de posição social fortemente associado com a renda (Kamakura, \& Mazzon, 2013).

Além disso, mesmo a diferenciação de grau entre corrupção e jeitinho, isto é, entre crimes de grande porte e infrações menores, é relativa: o que é um ato ilegal menor ou maior? Não há definições absolutas, mas avaliações subjetivas; para uns, um prejuízo de um 
salário mínimo é algo enorme, para outros, não declarar algumas dezenas de milhares de reais em imposto não é grande coisa. Isto é, mesmo que conceitualmente se possa buscar definir uma diferença de intensidade ou tamanho da prática do jeitinho e da corrupção, nada impede que para as pessoas, de modo geral, esses entendimentos se confundam e flexibilizem.

O jeitinho se mostra mais uma vez como uma ideologia conservadora porque a percepção do Brasil como "país que não tem jeito" estimula o comportamento egoísta e individualista, desconsiderando o funcionamento igualitário e impessoal das instituições. As pessoas em melhores condições para se beneficiar desse cenário são de classes sociais favorecidas, que podem mobilizar mais recursos - econômicos, culturais e sociais - em proveito próprio, extraindo mais vantagens de expedientes na linha do jeitinho. Como resultado, é difícil prever algo que não a manutenção ou a exacerbação das desigualdades sociais, reforçando as diferenças de poder existentes na sociedade brasileira.

\section{Considerações finais}

Neste trabalho, buscamos tanto fazer uma análise crítica e compreensiva dos estudos sobre jeitinho nas ciências humanas quanto desenvolver a tese de que o jeitinho brasileiro opera como uma ideologia, aumentando as desigualdades sociais. O trabalho de revisão visou a identificar e discutir as convergências e diferenças de algumas das contribuições fundamentais sobre a temática. A segunda parte do trabalho parte de uma definição de jeitinho que procura respeitar a diversidade das perspectivas sobre o fenômeno e de um conceito relativamente aberto de ideologia para defender a tese de que o jeitinho tem efeitos ideológicos, devendo muito à análise crítica de Souza (2015). Buscamos embasar nossa argumentação em pesquisas brasileiras e internacionais das ciências sociais e da psicologia social com resultados pertinentes a respeito do jeitinho e comportamentos corruptos.

Nossa posição pode ser resumida no entendimento de que o problema principal representado pelo jeitinho é a disseminação da percepção generalizada do Brasil de modo negativo e essencialista, como se a corrupção e a ilegalidade fizessem parte do código genético de sua população. São obstáculos graves para o desenvolvimento do país e seu povo, mas há uma diferença importante entre considerar esses aspectos como patrimônio cultural brasileiro e patrimônio da humanidade. No segundo caso, identifica-se um problema a ser combatido por estratégias institucionais e psicossociais; no primeiro, não temos um país em construção, mas já construído, entregue a um destino pessimista, o que leva ao descompromisso com o ataque a suas contradições e tende a reproduzir a situação atual indefinidamente por meio de práticas individualistas que a retroalimentam.

Os desenvolvimentos teóricos aqui apresentados ainda são interpretações incipientes e propositivas, que podem inspirar verificação empírica. No campo da psicologia social, estudos empíricos correlacionais e experimentais envolvendo as variáveis posição ou classe social, frequência de prática do jeitinho, atitudes frente ao jeitinho, identificação com a nacionalidade e cultura brasileira e outros fenômenos associados fornecerão informações para fortalecer, questionar e refinar algumas das relações aqui sustentadas, sofisticando o entendimento conceitual e explicativo sobre o jeitinho. 
A crítica da ideologia permite discutir as decorrências e condições para as interpretações da sociedade. Esperamos que esta modesta contribuição tenha demonstrado alguns dos efeitos do jeitinho nesse nível, justificando razões para seu combate.

\section{Referências}

Almeida, A. C. (2012). A cabeça do brasileiro (5a ed.). Rio de Janeiro: Record.

Barbosa. L. (2005). Jeitinho brasileiro. A arte de ser mais igual que os outros (6a ed.). Rio de Janeiro: Campus.

Bourdieu, P. (1986). The forms of capital. In J. Richardson (Ed.), Handbook of theory and research for the sociology of education (pp. 241-258). Westport: Greenwood.

Cialdini, R. B., Kallgren, C. A., \& Reno, R. R. (1991). A focus theory of normative conduct: a theoretical refinement and reevaluation of the role of norms in human behavior. In M. Zanna (Ed.). Advances in experimental social psychology (v. 24, pp. 201-234). New York: Academic Press. doi: 10.1016/S00652601(08)60330-5.

DaMatta, R. (1997). Carnavais, malandros e heróis. Para uma sociologia do dilema brasileiro (6ạ. ed.). Rio de Janeiro: Rocco.

DaMatta, R. (1986). O que faz o brasil, Brasil? Rio de Janeiro: Rocco.

Dubois, D., Rucker, D. D., \& Galinsky, A. D. (2015). Social class, power and selfishness: when and why upper and lower class individuals behave unethically. Journal of Personality and Social Psychology, 108(3), 436-449. doi: $10.1037 /$ pspi0000008.

Ferreira, M. C., Fischer, R., Porto, J. B., Pilati, R., \& Milfont, T. L. (2012). Unraveling the mystery of Brazilian jeitinho: a cultural exploration of social norms. Personality and Social Psychology Bulletin, 38(3), 331344. doi: 10.1177/0146167211427148.

Fischer, R., Ferreira, M. C., Milfont, T., \& Pilati, R. (2014). Culture of corruption? The effects of priming corruption images in a high corruption context. Journal of Cross-Cultural Psychology, 45(10), 1594-1605. doi: $10.1177 / 0022022114548874$.

Holanda, S. B. (1995). Raízes do Brasil (26a. ed.). São Paulo: Companhia das Letras.

Kamakura, W. A., \& Mazzon, J. A. (2013). Estratificação socioeconômica e consumo no Brasil. São Paulo: Blucher.

Köbis, N. C., van Prooijen, J.-W., Righetti, F., \& Van Lange, P. A. M. (2015). “Who doesn't?" - The impact of descriptive norms on corruption. PLOS ONE, 10(6), 1-14. doi: 10.1371/journal.pone.0131830.

Miura, M. A. (2012). Entre a simpatia e a corrupção: análise das dimensões constituintes do jeitinho brasileiro. Dissertação de mestrado, Universidade de Brasília, Brasília. Recuperado em 8 de junho, 2016, de http://repositorio.unb.br/bitstream/10482/10431/1/2012_MarcoAkiraMiura.pdf.

Piff, P. K., Stancato, D. M., Côté, S., Mendoza-Denton, R., \& Keltner, D. (2012). Higher social class predicts increased unethical behavior. PNAS, 109(11), 4086-4091. doi: 10.1073/pnas.1118373109.

Pilati, R., Milfont, T. L., Ferreira, M. C., Porto, J. B., \& Fischer, R. (2011). Brazilian jeitinho: understanding and explaining an indigenous psychological construct. Interamerican Journal of Psychology, 45(1), 27-36.

Resende, M. M. (2015). Jeitinho brasileiro tem jeito? O efeito do jeitinho brasileiro e da identidade moral no comportamento ético nas organizações. Dissertação de mestrado. Recuperada de http://repositorio.unb.br/handle/10482/19932.

Rodrigues, N. (1993). Complexo de vira-latas. In R. Castro (Ed.). À sombra das chuteiras imortais. Crônicas de futebol (pp. 51-52). São Paulo: Companhia das Letras.

Smith, P. B., Huang, H. J., Harb, C., \& Torres, C. (2012). How distinctive are indigenous ways of achieving influence? A comparative study of guanxi, wasta, jeitinho and "pulling strings". Journal of Cross-Cultural Psychology, 43(1), 135-150. doi: 10.1177/0022022110381430. 
Smith, P. B., Torres, C., Leong, C.-H., Budhwar, P., Achoui, M., \& Lebedeva, N. (2011). Are indigenous approaches to achieving influence in business organizations distinctive? A comparative study of guanxi, wasta, jeitinho, svyazi and pulling strings. International Journal of Human Resource Management, 23(2), 333-348. doi: 10.1080/09585192.2011.561232.

Souza, J. (2015). A tolice da inteligência brasileira: ou como o país se deixa manipular pela elite. São Paulo: LeYa.

Thompson, J. B. (2011). Ideologia e cultura moderna. Teoria social crítica na era dos meios de comunicação de massa (9ạ ed., Grupo de Estudos sobre Ideologia, Comunicação e Representações Sociais da PósGraduação do Instituto de Psicologia da PUC-RS). Petrópolis: Vozes. (Trabalho original publicado em 1990).

Torres, C. V., Alfinito, S., Galvão, C. A. S. P., \& Tse, B. C. Y. (2015). Brazilian jeitinho versus Chinese guanxi: investigating their informal influence on international business. Revista de Administração Mackenzie, 16(4), 77-99. doi: 10.1590/1678-69712015/administracao.v16n4p77-99

Transparency International (2013). Global corruption barometer 2013. Retrieved from https://www.transparency.org/gcb2013/report.

Transparency International (2016). Corruption Perceptions Index 2015. Retrieved from https://www.transparency.org/cpi2015/.

Wilson, R. W. (1992). Compliance ideologies. Rethinking political culture. Nova lorque: Cambridge University Press. 